\title{
Work from Home during COVID 19 and Gender Differences in Twitter Content Analysis
}

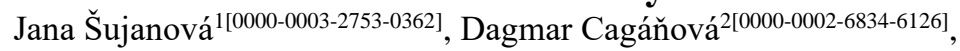 \\ Rudolf Husovič $\left.{ }^{2[0000-0002-3791-1647}\right]$, Renata Nováková1[0000-0003-3106-2709], \\ Gabriela Pavlendová 3 [0000-0003-4558-9464] \\ ${ }^{1}$ Institute of Management, University of Ss. Cyril and Methodius in Trnava, Hajdóczyho 1, \\ Trnava Slovak Republic \\ ${ }^{2}$ Institute of Industrial Engineering and Management, Faculty of Materials Science and Tech- \\ nology in Trnava, Slovak University of Technology in Bratislava, ul. J. Bottu 25, Trnava, Slo- \\ vak Republic \\ Department of Physics, Faculty of Civil Engineering, Slovak University of Technology in Bra- \\ tislava, Radlinského 11, Bratislava \\ jana.sujanova@ucm.sk
}

\begin{abstract}
In the introduction of this article, the authors of the paper present the current state of the job market in the European Union. There are several factors that will influence the structure of the future workforce: demographic changes, and changes caused by unpredictable crisis, such as COVID-19. It is evident from the presented statistics, that there are gender differences and risks influencing their job positions involved. The authors present the research oriented on the differences between genders and their attitudes toward working from home. A method of qualitative analysis of the tweets collected during the period of ten days was used. Data analysis was executed with the MAXQDA software. The results of the analysis did not prove the assumption that there are differences between genders.
\end{abstract}

Keywords: COVID-19, Working from home, Qualitative analysis, Twitter, Gender differences

\section{Introduction}

"The only thing we know about the future is that it will be different." Peter F. Drucker

Today, we are facing the biggest global crisis ever. It has influenced everything from the economy to education systems, from the way we move and shop to the way we work. No area in our lives has not been impacted by the COVID-19 crisis. However, the crisis has not had an equal gender impact.

\subsection{Future labour market in the European Union}

The European Union labour market will go through major changes in the next thirty years. In the (Chopin and Foucher, 2017), it was revealed how economic growth and 
productivity are linked to key indicators in population figures. The report predicted that in 2050, North America should see its population rise by 75 million inhabitants (two times less than the number for South America), Europe of 28 (EU-28) could stagnate in 2050 at approximately 500 million people, while losing 49 million people of working age (20-64). That represents around 11 million potentially-active workers fewer in Germany, and 7 to 8 million fewer in Spain and Italy. Meanwhile, France will be content to catch up with Germany; something the United Kingdom will likely achieve even earlier.

To balance the decrease of the active workforce, the European Union can consider the following options (Cagáňová et al. 2017, Švač, Cagáňová 2020):

1. Internal and External sources of the workforce.

2. Bridging of the skills gap.

3. Increase of productivity.

As for the mobilisation of internal sources, EU is considering the following options (Cagáňová et al. 2017):

1. Prolongation of the retirement age.

2. More women in the labour process.

3. Stopping of the brain drain from individual countries.

According to (Manyika 2017), women represent one of the largest pools of untapped labour: globally, 655 million fewer women are economically active than men. Eliminating gender gaps in employment and wages would allow companies to make better use of the available talent pool, with potential growth implications.

There is evidence that having women on boards and in senior management positions has a positive impact on companies ${ }^{e e}$ performance and profitability (Kochhar et al. 2017). One of the policy responses to the situation of the female labour force was the "Proposal for a Directive of the European Parliament and the Council on work-life balance" (European Commission 2017) the preconditions for a higher involvement of women in the labour market:

1. Maternity leave.

2. Paternity leave.

3. Parental leave.

4. Careers' leave.

5. Flexible working arrangements.

The COVID-19 crisis has fostered us to reconsider the existing workforce structure, mainly the women's involvement in the labour market. In ILO Monitor (ILO 2020), among those workers significantly impacted by the crisis in the informal economy are women, overrepresented in high-risk sectors $(42 \%$ of women workers are working in those sectors, compared to $32 \%$ of men)

In the formal economy, the high-risk jobs according to (Chinn et al. 2020) are customer services and sales, food service, building and others (see Figure 1). 
European jobs potentially at risk, by job cluster, millions, \% share of total cluster employment ${ }^{1}$

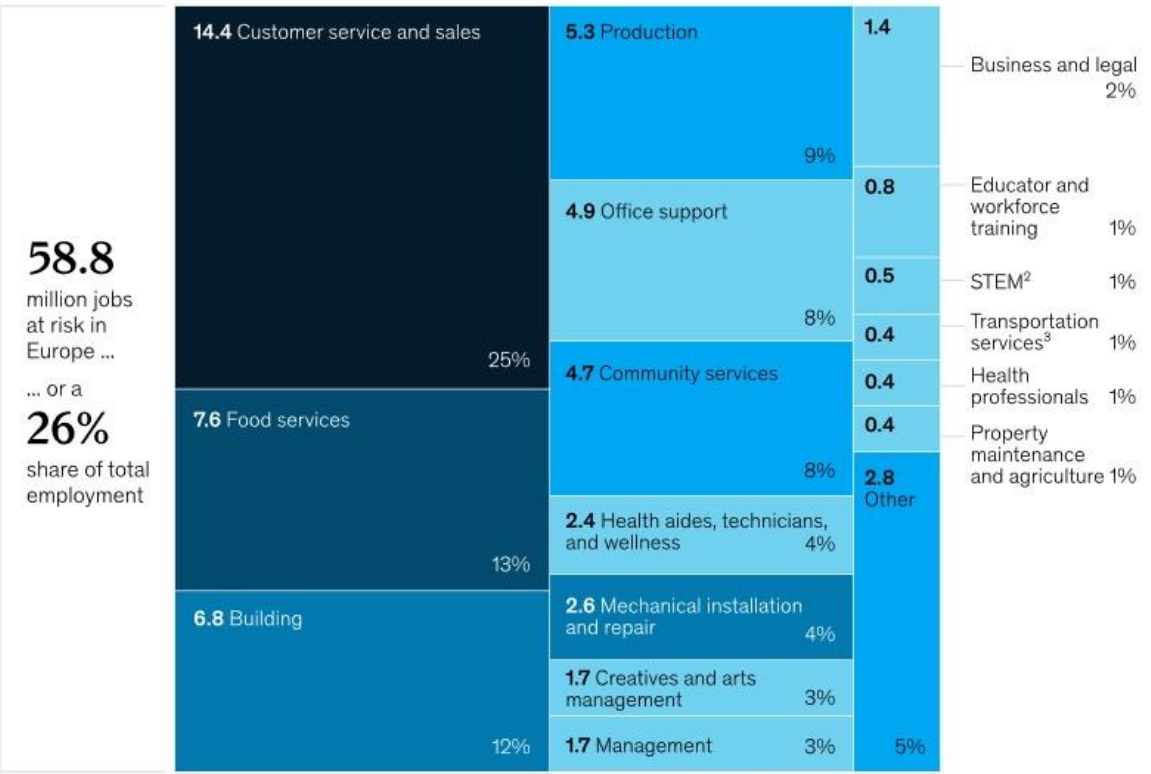

Note: Analysis determines jobs at risk based on physical-distancing policies and their immediate knock-on economic consequences; assumes level of physical distancing (defined by shelter-in-place policy) based on state policies. Figures may not sum to $100 \%$, because of rounding. 'Age groups as provided in employment statistics by Eurostat; further differentiation not possible, because of data limitations.

Source: Eurostat; LaborCube; McKinsey analysis

Fig. 1. European jobs potentially at risk, by job clusters Source: (Chinn et al. 2020) [7]

Based on the education level, jobs requiring a secondary level of education are riskier than primary and tertiary education level jobs (see Figure 2). 
European jobs potentially at risk, by industry sector and education level, $\%$ share of total sector employment

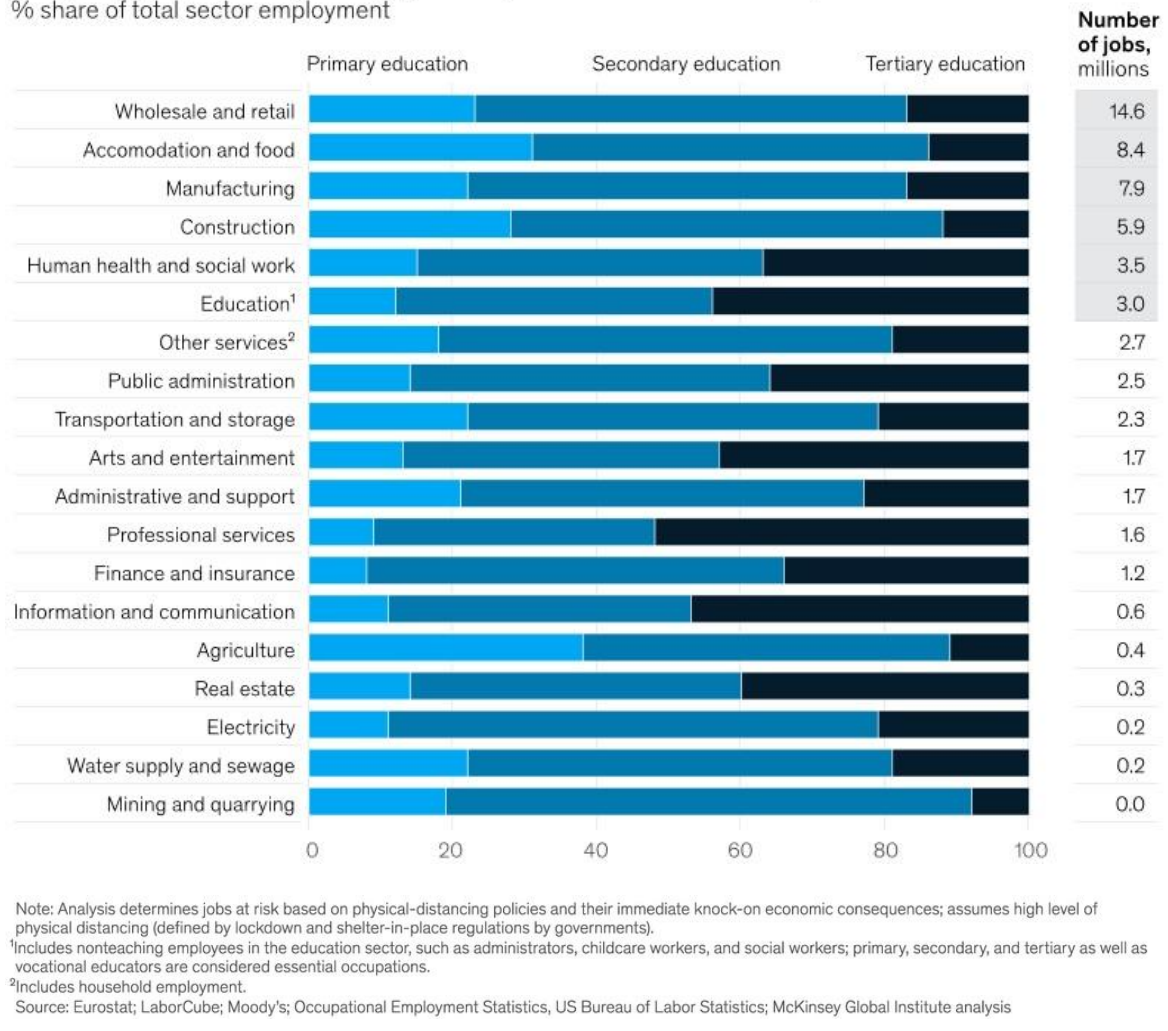

Fig. 2. European jobs potentially at risk, by industry sector, $\%$ share of total sector employment Source: (Chinn et al. 2020)

From the above-mentioned statistics, it is evident that jobs mostly occupied by women are the most vulnerable professions influenced by the crisis. It is not clear yet how will these jobs recover after the crisis.

Flexible working arrangements were also recognized as one of the areas with a positive impact during the monitored period from 2015 to 2019, published in McKinsey report (Huang et al. 2019) (see Figure 3). 
Progress over the years for women ${ }^{1}$

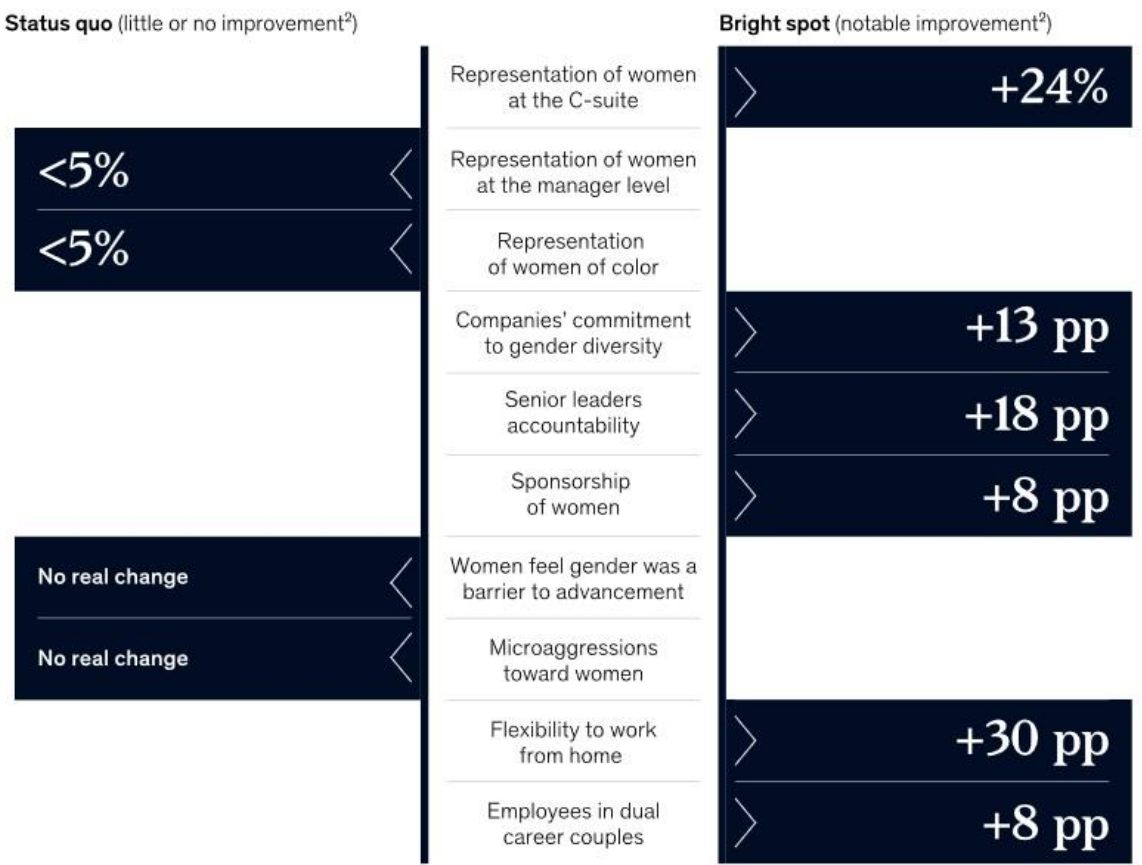

Fig. 3. Progress over the years for women Source: (Huang et al. 2019) [8]

During the pandemic, women and men have had different experiences with working from home. According to (Rogers 2020), women find working from home to be more detrimental to their professional lives than men:

- "Men are nearly twice as likely as women to claim the amount they are able to work from home has positively affected their career during the pandemic: $57 \%$ of men say it has been positive, while only $29 \%$ of women say the same

- $67 \%$ of men say they have become more productive since they have been working from home during the pandemic, while $41 \%$ of women say the same

- Men are 2.3 times more likely to claim working from home for an extended period of time would positively affect their career progression: $71 \%$ of men said so, while only $31 \%$ of women said the same; though nearly a half of women said working from home would neither positively nor negatively affect their career, while only $20 \%$ of men held that opinion."

In the same report (Rogers 2020), men with children at home report positive effects on their career much more frequently than women:

- "34\% of men with children at home say they have received a promotion while working remotely, while only $9 \%$ of women with children at home say the same 
- $26 \%$ of men with children at home say they have received a pay raise while working remotely, while only $13 \%$ of women with children at home say the same

- $29 \%$ of men with children at home say they have taken on additional leadership while working remotely, while only $10 \%$ of women with children at home say the same

- $28 \%$ of men with children at home say they have been given responsibility for important projects while working remotely, while only $10 \%$ of women with children at home say the same

- $19 \%$ of men with children at home say they have received praise or recognition inside the company while working remotely, while only $10 \%$ of women with children at home say the same

- $15 \%$ of men with children at home say they have received positive formal reviews while working remotely, while only $7 \%$ of women with children at home say the same."

An interesting fact mentioned in the report (Rogers 2020) is that men were able to work from home more often than women before the pandemic:

- "Men are more than twice as likely to say they were occasionally allowed to work from home before COVID-19: 66\% of men say they could, while only 31\% of women say the same

- The majority of men and women want more work-from-home time in the future: $71 \%$ of men say they'd like to work from home more, while $56 \%$ of women say the same."

The COVID-19 pandemic and lockdowns around the EU and other countries caused around $50 \%$ of the workers to be working from home. In (McKinsey\&Company COVID Response Center 2020), the authors stated that "Remote working is creating and exposing divides in living set-ups, divides in the ways people and organizations get work done, and divides in our individual needs for social interaction."

Based on the fact that women are working in the professions negatively affected by the COVID-19 crisis and the authors' experiences in gender diversity (Cagáňová et al. 2012, Šujanová et al. 2012, Cagáňová et al. 2012), the following research was oriented on the gender differences regarding the perception of working from home presented on Twitter.

\section{$2 \quad$ Research method}

As a research method, the authors of the paper have used qualitative analysis based on the content analysis. The authors of the paper have analysed tweets collected during ten-day period (from $29^{\text {th }}$ August 2020 to $3^{\text {rd }}$ September 2020). The tweets have been retrieved from Twitter according to the hashtag "\#workfromhome." The collected tweets have been limited to tweets in English language.

For qualitative analysis, the authors of the paper have used MAXQDA software (MAXQDA 1995). 
The authors of the paper have analysed 12,093 tweets and 599 replies. The collected data were cleaned using the MAXQDA Standard Stop list (conjunctions, prepositions, pronouns, and single letters). The second cleaning was done by eliminating strings without meaning, names, and other irrelevant words or characters.

\subsection{Words and hashtags tweets analysis}

For the basic tweet analysis, the authors of the paper have used the MAXQDA function "Analyse tweets." From this analysis, the authors of the paper obtained the most frequently used words (see Figure 4). These results were later used for the identification of relevant words for coding of the tweets. The next result achieved by applying this analysis was the list of the most frequently used hashtags (see Figure 5).

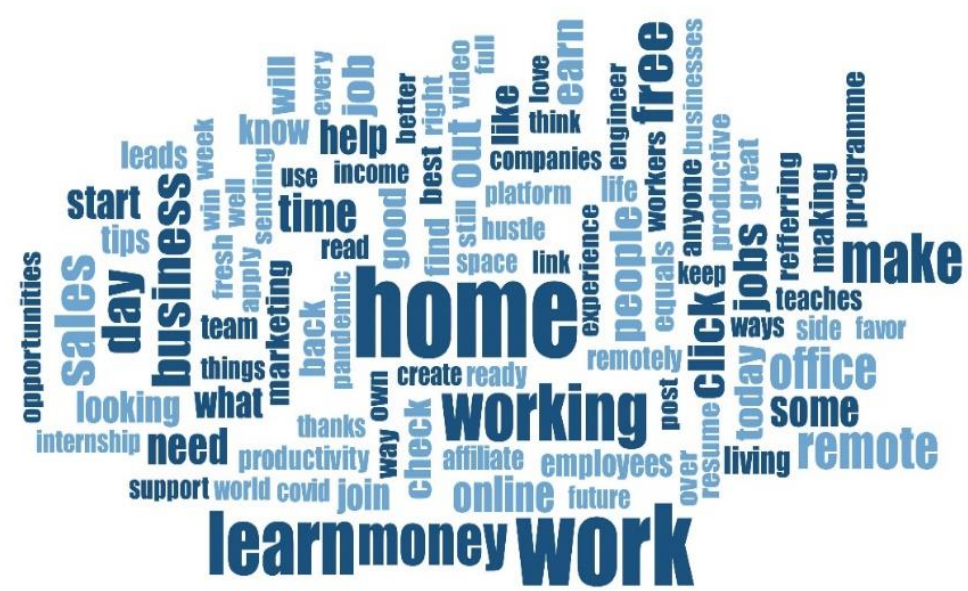

Fig. 4. Word frequencies of the tweets (minimum frequency 10) Source: The authors of the paper 


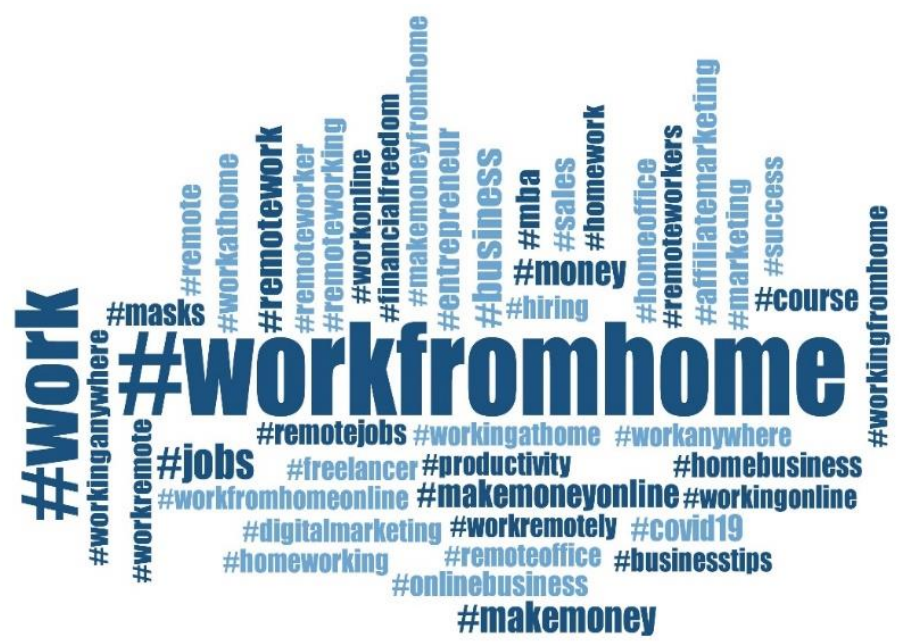

Fig. 5. Hashtag frequencies of the tweets (45 most frequently used hashtags) Source: The authors of the paper

\section{$2.2 \quad$ Text coding}

To analyse the collected data, the authors of the paper have used a coding set based on the keywords: learning, training, course, skills, development career, chance, opportunity, salary, wages, payment, money, government, employers, management, independence, freedom, men, man, women, woman, diversity, equality, equal.

Coding based on the keywords was used for the selection of tweets with the content relevant to the research aim - perception on work from home.

The selection of keywords was oriented on following areas:

1. Personal development: learning, training, course, skills

2. Work position: development career, chance, opportunity

3. Payment: salary, wages, payment, money

4. Stakeholders: government, employers, management

5. Feelings: independence, freedom

6. Gender differences: men, man, women, woman, diversity, equality, equal.

The first level of coding was done by a lexical search of collected tweets, where the authors of the paper have obtained 10,244 matches.

The second level of coding focused on the content of the tweets, containing identified keywords from the first level coding.

\subsection{Content analysis results}

From the analysed tweets, around $98 \%$ have been tweets promoting companies or individuals. Most of the companies offered training in different areas like: 
- Financial services

- Health services

- Marketing

- Sale

- Other trainings related to the online jobs.

Individuals preferably offered services related to the education.

Another category of the offers were services for companies related to working from home:

- General IT services

- Cyber security services

- Human resources development

- Health services related to the negative impact of the work from home.

A specific category of such services were job offers.

There has only been one organization offering special training and consulting from women - SHEROSE in India (Shah 2018). Positive reactions have been published on the opportunity given to women in IT training through the Sabio training programme (Sabio 2020).

There have also been offers for individual development:

- Time management

- Communication and presentation skills

- Online team work and collaboration

- IT training of online applications

- Work-life balance

- Fitness.

Those $2 \%$ of tweets that have not been marketing-oriented, have the authors of the paper divided to two categories:

- Positive

- Negative.

The authors of the paper have categorised the tweets presenting positive attitude of the authors as:

- Motivational: authors shared quotes to encourage others.

- Complimentary: authors expressed their gratitude to the employers and management for their attitude to the employees during the crisis.

- Knowledge sharing: in these tweets' authors shared articles and web sites related to the work from home organization (the collection of the articles is accessible at https://www.one-tab.com/page/kg9nblrEReO6rmZQa-Ie8g).

- Experience sharing: authors shared their experience as online freelancers or selfemployers.

- Humour: where authors make jokes about themselves and changes in their habits. 
Negative tweets have been categorised as:

- Critical: expressing negative attitude toward government regulations or company management.

- Complaints: mostly complaints related to the cuts in salaries or loss of jobs.

- Social: related to the lack of social contacts.

\section{Conclusions}

The contents of the 12,692 tweets containing \#workfromhome, collected during the period from $29^{\text {th }}$ August 2020 to $3^{\text {rd }}$ September 2020, did not prove gender differences between in their perception on work from home. The authors of the paper have identified two good practices in supporting women in working from home: SHEROSE and Sabio. As a positive, the authors of the paper also consider that women have been encouraged to gain new IT skills, not only as graphic or text creators or editors, but also in programming. There have also been positive experiences that women share about working from home as independent self-employers.

More than $60 \%$ of positive tweets have been published by women. Women did not complain about government or management.

\section{Acknowledgements}

This paper has been written with the support of H2020 project "Linking Research and Innovation for Gender Equality”, Nr. 873134, acronym CALIPER and Erasmus plus project Arphymedes.

\section{References}

1. Cagáňová, Dagmar; Saniuk, Anna; Šujanová, Jana; Horňáková, Natália; Švač, Vladimír (2017): Managerial skills in industrial praxis. Zielona Góra: Wydawnictwo Instytutu Informatyki i Zarządzania Produkcją Uniwersytetu Zielonogórskiego.

2. Švač, Vladimír; Cagáňová, Dagmar. (2020): Managerial Skills for Innovation Support. In Mobile Networks and Applications. Vol. 25, iss. 3 (2020), s. 925-931. ISSN 1383-469X

3. European Commission (2017): Directive of the European Parliament and the Council on work-life balance for parents and carers and repealing Council Directive 2010/18/EU. European Commission. Available online at https://eur-lex.europa.eu/legal-content/EN/TXT/HTML/?uri=CELEX:52017PC0253\&from=EN, checked on 3/30/2020.

4. Huang, Jess; Krivkovich, Alexis; Starikova, Irina; Yee, Lareina; Zanoschi, Delia (2019): Women in the Workplace 2019. In McKinsey \& Company, 2019. Available online at https://www.mckinsey.com/featured-insights/gender-equality/women-in-the-workplace2019, checked on 5/31/2020.

5. Chinn, David; Klier, Julia; Stern, Sebastian; Tesfu, Sahil (2020): Safeguarding Europe's livelihoods: Mitigating the employment impact of COVID-19. In McKinsey \& Company, 2020. Available online at https://www.mckinsey.com/industries/public-and-social-sector/our-insights/safeguarding-europes-livelihoods-mitigating-the-employment-impact-ofcovid-19, checked on 5/31/2020. 
6. Chopin, Thierry; Foucher, Michel (Eds.) (2017): Schuman Report 2017 on Europe. The state of the Union. Fondation Robert Schuman. 11th edition. Paris: Lignes Reperes.

7. ILO (2020): ILO Monitor: COVID-19 and the world of work. Fifth edition Updated estimates and analysis. ILO.

8. Kochhar, Kalpana; Jain-Chandra, Sonali; Newiak, Monique (2017): Women, work, and economic growth. Leveling the playing field / editors, Kalpana Kochhar, Sonali Jain-Chandra, and Monique Newiak. Washington, D.C.: International Monetary Fund.

9. Manyika, James (2017): Technology, jobs, and the future of work. In McKinsey \& Company, 5/24/2017. Available online at https://www.mckinsey.com/featured-insights/employment-and-growth/technology-jobs-and-the-future-of-work, checked on 4/30/2020.

10. MAXQDA (1995): MAXQDA: All-In-One Qualitative \& Mixed Methods Data Analysis Tool. Available online at https://www.maxqda.com/, checked on 8/31/2020.

11. Pawar, Kishori; Shrishrimal, P.; Deshmukh, Ratnadeep R. (2015): Twitter Sentiment Analysis: A Review. ResearchGate. Available online at https://www.researchgate.net/publication/277554643_Twitter_Sentiment_Analysis_A_Review, updated on 8/31/2020, checked on $8 / 31 / 2020$.

12. Rogers, Ben (2020): Not in the same boat: Career progression in the pandemic. Qualtrics. Available online at https://www.qualtrics.com/blog/inequitable-effects-of-pandemic-on-careers/, checked on 8/27/2020.

13. Huang, Jess; Krivkovich, Alexis; Starikova, Irina; Yee, Lareina; Zanoschi, Delia (2019): Women in the Workplace 2019. In McKinsey \& Company, 2019. Available online at https://www.mckinsey.com/featured-insights/gender-equality/women-in-the-workplace2019, checked on 5/31/2020.

14. Chinn, David; Klier, Julia; Stern, Sebastian; Tesfu, Sahil (2020): Safeguarding Europe's livelihoods: Mitigating the employment impact of COVID-19. In McKinsey \& Company, 2020. Available online at https://www.mckinsey.com/industries/public-and-social-sector/our-insights/safeguarding-europes-livelihoods-mitigating-the-employment-impact-ofcovid-19, checked on 5/31/2020.

15. McKinsey\&Company COVID Response Center (2020): Bridging the new divides. McKinsey\&Company. Available online at https://www.businessbusinessbusiness.com.au/how-the-work-from-home-revolution-affects-the-value-of-your-business/?utm_source=rss\&utm_medium=rss\&utm_campaign=how-the-work-from-home-revolution-affects-the-value-of-your-business, updated on 6/21/2020, checked on 8/7/2020.

16. Cagáňová, Dagmar; Čambál, Miloš; Šujanová, Jana; Woolliscroft, Paul; Holeček, Jaroslav. (2012): Gender Diversity Research in the Slovak Republic and the Participation of Women in Top Management Positions in Science and Research. In Advanced Materials Research : 3rd International Conference on Manufacturing Science and Engineering (ICMSE 2012), China, 27-29 Marec 2012. s.136-148. ISSN 1022-6680

17. Šujanová, Jana; Čambál, Miloš; Cagáňová, Dagmar; Holeček, Jaroslav; Pavlenda, Pavel. (2012): Gender diversity in science and research in the Slovak Republic. In EAEEIE 2012 : 23rd EAEEIE Annual Conference, Cagliari, Italy, February, 26-27, 2012. Cagliari : University of Cagliari, 2012, s.[2].

18. Cagáňová, Dagmar; Štefánková, Jana; Šujamová, Jana. (2010): Improving gender awareness in the period of an economic crisis. In Proceedings of the Joint International IGIP-SEFI : Annual Conference 2010. Diversity unifies - Diversity in Engineering Education, 19th - 22 th September 2010, Trnava, Slovakia. Brussel : SEFI, 2010. ISBN 978-2-87352-003-8.

19. Sabio (2020): Sabio - Learn To Code - Programs. Sabio. Available online at https://sabio.la/training, checked on 9/2/2020. 
20. Shah, Priya Florence (2018): Work From Home For Women In India. In Naaree Admin, 8/30/2018. Available online at https://www.naaree.com/work-from-home-india/, checked on $9 / 3 / 2020$. 